
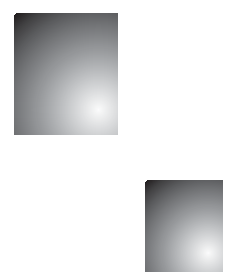

\title{
Aprendizagem de Gestores no Contexto das Transformações Contemporâneas no Mundo do TrabalHO
}

\author{
Managerial Learning in the Contemporary Transformations
} Context in the World of Work

Lisiane Closs

Professora Adjunta. Escola de Administração da Univesidade Federal do Rio Grande do Sul-UFRGS. Porto Alegre, RS. Brasil. E-mail: lisiane.closs@ufrgs.br

Claudia Simone Antonello

Professora Adjunta. Escola de Administração da UFRGS. Porto Alegre, RS. Brasil. E-mail: csantonello@ea.ufrgs.br

\section{Resumo}

O objetivo desta pesquisa é aprofundar a compreensão sobre como ocorreram os processos de aprendizagem de gestores ao longo de suas vidas, destacando as aprendizagens decorrentes das principais transformações percebidas no contexto contemporâneo no mundo do trabalho a partir do uso do método de história de vida. Os resultados revelam que os diferentes processos de aprendizagem de gestores, inseridos em um contexto com expectativas sociais que se assemelham, relacionam-se a seus estágios de vida e de desenvolvimento na carreira, bem como às mudanças e experiências vivenciadas por eles. É possível verificar, também, novas aprendizagens gerenciais decorrentes de transformações contemporâneas, evidenciando algumas carências no que tange a qualidades humanas como relações interpessoais, saber trabalhar coletivamente, intuição, comunicação, estabilidade emocional, as quais exigem constantes autocríticas e aprendizagens e não foram contempladas pela educação gerencial.

Palavras-chave: Aprendizagem. Desenvolvimento. Aprendizagem Gerencial. Transformações Contemporâneas. História de Vida.

\section{Abstract}

The objective of the research is to deepen understanding of how learning processes of managers occurred throughout their lives, highlighting the learning arising from major changes perceived in the contemporary context, using the life history method. The results show that different learning processes of managers, inserted in a context with similar social expectations, relate to their life stages and career development as well as to their lived experiences and changes. There was also new management learning arising from contemporary transformations, demonstrating some deficiencies regarding human qualities such as interpersonal relationships, ability to work collectively, intuition, communication and emotional stability, which require constant self-criticism and learning and which were not contemplated by management education.

Keywords: Learning. Development. Management Learning., Contemporary Transformations. Life History. 


\section{INTRODUÇÃo}

As organizações tornaram-se centrais no contexto contemporâneo, sendo, concomitantemente, causa e efeito das principais mudanças ocorridas nos últimos tempos, interferindo não somente em espaços de trabalho, mas também na esfera pessoal e familiar dos indivíduos. Elas afetam, direta ou indiretamente, a vida da maioria da população mundial, seja na geração de emprego e renda, seja na produção de bens e serviços, seja na criação de subprodutos intencionais e não intencionais, os quais trazem resultados tanto benéficos como nocivos à sociedade e ao meio ambiente (AXLEY; MCMAHON, 2006). O papel dos gestores, neste contexto, ganha importância na sociedade como um todo, não se restringindo apenas ao âmbito das organizações.

As transformações no contexto contemporâneo, envolvendo especialmente a globalização da economia, a maior capacidade de acesso a informações globais e de seu processamento devido à redução de fronteiras nos negócios, sobretudo a partir dos anos de 1990, aumentaram a competitividade em todos os setores, gerando necessidades de mudanças nas formas de gerir as organizações. Entre seus principais impactos estão: a necessidade de reestruturações organizacionais; a ênfase à gestão empreendedora; a valorização de lideranças morais e de responsabilidade social corporativa, originadas por crises éticas e problemas ambientais globais; a exigência de habilidade no uso e no gerenciamento de informações para a tomada de decisões; a necessidade de gerenciamento pró-ativo e consciente do conhecimento; a capacidade de inovação e mudança, como diferenciais em um ambiente turbulento e de rápidas mudanças (HALLINGER; SNIDVONGS, 2008). A importância da aprendizagem de gestores, em função dessas novas necessidades e expectativas, demanda o aprofundamento da questão da dinâmica de seus processos de aprendizagem. (DANIS; SOLAR, 2001)

Poucas pesquisas, entretanto, foram realizadas sobre o tema no Brasil e nenhuma delas foi desenvolvida utilizando o método de história de vida, adotado no presente estudo. Esse método engloba, entre seus desafios, a representação de aspectos comuns e únicos simultaneamente, conectando 'estórias' individuais ao contexto mais amplo da sociedade (DENZIN, 1989). Assim, o objetivo central da pesquisa aqui apresentada é o de aprofundar a compreensão sobre como ocorreram os processos de aprendizagem de gestores, durante suas vidas, destacando suas aprendizagens decorrentes das principais transformações percebidas no contexto contemporâneo.

\section{Desenvolvimento e Aprendizagem de Adultos}

A área de pesquisas sobre aprendizagem beneficia-se da integração do estudo de aspectos relativos ao desenvolvimento individual ou coletivo dos adultos (DANIS; SOLAR, 2001). Merriam e Caffarella (1999) destacam a importância da compreensão de como adultos desenvolvem-se e mudam, ao longo dos anos, e de como questões ligadas ao desenvolvimento e às mudanças motivam e interagem com a aprendizagem de adultos, considerando

[...] conteúdos de aprendizagem complexos e interligados, aprendizagens realizadas no quadro de processos de longa duração, frequentemente empreendidas por pessoas inseridas em situações particulares e em contextos sociais reais. (DANIS; SOLAR, 2001, p. 15)

Conforme Danis e Solar (2001), a aprendizagem alimenta o desenvolvimento pessoal, cognitivo e metacognitivo e o desenvolvimento fomenta a aprendizagem, como processo ou construção e não somente como um produto ou resultado. As contribuições teóricas sobre o desenvolvimento de adultos, concebido como uma evolução ao longo da vida, em função de um contexto e de um meio de vida particulares, de acordo com Danis (2001), são exploradas a seguir.

Sob a perspectiva psicológica, Clark e Caffarella (1999) identificam três categorias de estudos acerca do desenvolvimento de adultos. A primeira delas, a do desenvolvimento psicológico sequencial, dominante na literatura científica até recentemente, define transformações a partir de estágios ou fases preestabelecidas. Segundo Merriam e Clark (1991), em uma mesma idade cronológica ou estágio de desenvolvimento, os adultos realizam tarefas semelhantes ou sofrem crises similares para poderem progredir para estágios posteriores de desenvolvimento.

A segunda categoria de estudos do desenvolvimento psicológico define a transformação a partir de 
acontecimentos que moldam e orientam a vida de cada adulto, sendo este capaz de modificar-se e adaptar-se desde os acontecimentos marcantes ocorridos em sua vida. Conforme Danis (2001, p. 30), "[...] o processo contínuo de maturação que subentende e caracteriza a experiência de vida do adulto, articular-se-ia, principalmente, em torno de conhecimentos relacionados seja com o trabalho, seja com a afectividade de cada indivíduo".

Para Merriam e Clark (1991), as dimensões trabalho $e$ afetividade são as principais forças vivas $e$ interativas que determinam o curso de vida de adultos, evoluindo em um contexto histórico-sociocultural particular, representando os principais modos de organização da experiência de adultos. A dimensão trabalho, para as autoras, inclui todas as experiências de trabalho, remuneradas ou não, e toda a formação formal realizada com o objetivo de inserção no mercado de trabalho. A dimensão afetividade inclui o conjunto de relações interpessoais, a vida familiar, social e as atividades de lazer. Acontecimentos marcantes nestas esferas, quer na forma de circunstâncias específicas, quer em processos que englobam o que procede $e$ sucede em determinadas situações, produzem-se especialmente em momentos de transição na vida de um adulto, favorecendo o desenvolvimento pessoal. (DANIS, 2001)

Merriam e Caffarella (1999) observam que transições originadas por eventos nas vidas das pessoas são processos que podem conduzir a aprendizagens e mudanças, embora não necessariamente o façam. Engajar-se em aprender é, muitas vezes, um modo de lidar com situações com as quais os adultos se defrontam, especialmente as relacionadas a trabalho e família, em épocas de transição. As mesmas autoras identificam que mais aprendizagens ocorrem em momentos de vida considerados bons, mas que os significados mais profundos dos eventos são extraídos de momentos difíceis.

A terceira categoria psicológica para o desenvolvimento de adultos, alicerçada basicamente em estudos com mulheres, fundamenta-se na noção de que relacionamentos são centrais para o desenvolvimento. Essa categoria utiliza a metáfora da rede de interconexões em constante mudança para descrever como mulheres/homens desenvolvem-se durante suas vidas. Ela destaca a importância dos relacionamentos e da colaboração para a aprendizagem, incluindo a importância crítica do reconhecimento de sentimentos. (MERRIAM; CAFFARELLA, 1999)

Sob a abordagem sociocultural, é o sistema de expectativa social que molda os processos de desenvolvimento (CLARK; CAFFARELLA, 1999). Fatores sociais e culturais são vistos como impulsionadores primários de mudanças e de crescimento na vida adulta. De acordo com Maclean, Harvey e Chia (2012a), os indivíduos podem ser compreendidos como produtos históricos de relações sociais, resultados de experiências e processos dinâmicos de construção de sentidos. Papéis sociais, tais como o de profissional, de pai/mãe ou de marido/ esposa, são determinados por expectativas sociais e mudam no tempo, assim como a determinação sobre em quais atividades os adultos devem se engajar e em que idade. Os conceitos de raça e gênero, bem como a orientação sexual, são, igualmente, construções sociais. (MERRIAM; CAFFARELLA, 1999)

No que tange à literatura sobre os aprendizes adultos, destaca-se a atenção conferida ao fenômeno da aprendizagem autodirigida/autônoma, uma habilidade que a sociedade complexa, em rápida mudança e desenvolvimento tecnológico, requer dos adultos (CRANTON, 2006). Conforme Knowles (1975), os adultos preferem aprendizagens autodirigidas, concebidas como o processo no qual a responsabilidade primária pelo planejamento, pela condução e pela avaliação do próprio aprendizado é assumida pelo aprendiz. Segundo Orvis e Ratwani (2010), o autodesenvolvimento de gestores envolve atividades voluntárias, realizadas com o objetivo de desenvolver suas capacidades e seu desempenho, sendo aprendizagens altamente individualizadas que atendem a suas necessidades únicas.

Sob o enfoque da aprendizagem experiencial, defendida por vários autores, e de acordo com Cranton (2006), o aprendizado ocorre mediante a interação entre indivíduo e meio ambiente, sendo um processo de tensão e conflito que envolve experiências concretas, ação e reflexão. A aprendizagem é um processo dinâmico que gera revisões permanentes dos conceitos aprendidos, sendo o conhecimento criado através da transformação da experiência.

Segundo Mezirow (1994), a aprendizagem transformadora envolve o processo de utilizar uma interpretação prévia para construir uma interpretação 
nova ou revisada do significado da experiência de alguém, a fim de guiar futuras ações. Ela objetiva transformações nos quadros de referência dos indivíduos, de modo consciente, por intermédio da reflexão crítica sobre pressupostos construídos de modo acrítico. Conforme o autor, a transformação de perspectivas e o reconhecimento do papel essencial desempenhado pela reflexão crítica suprem lacunas importantes, na teoria sobre aprendizagem de adultos, e possibilitam a conscientização de por que se atribui determinado sentido à realidade.

\subsection{Aprendizagem Gerencial}

Alguns dos caminhos encontrados pelos gestores para buscar novas aprendizagens concretizam-se pela educação formal, pela realização de cursos, pela participação em workshops e eventos, dentre outras atividades. $\mathrm{O}$ processo de aprendizagem que ocorre por meio dessas ações formais é voltado para a formação técnico-profissional e para o desenvolvimento de competências técnicas, envolvendo, sobretudo, procedimentos para a formulação e a implementação de estratégias e práticas gerenciais (SILVA, 2008). Em busca da colocação profissional, os programas de MBA (Master in Business Administration - voltados para a educação gerencial) são apresentados como uma via em um mundo globalizado e com muitas oportunidades para os mais qualificados (WOOD JR; PAES DE PAULA, 2004). Diversas críticas, no entanto, vêm alvejando o ensino em administração e as aprendizagens possibilitadas por seus programas.

A corrente inspirada inicialmente por Mintzberg, que enfatiza a aprendizagem experiencial, questiona a eficácia dos programas de MBA, os acusando de não capacitar para a gestão, embora façam crer que capacitem (WOOD JR; PAES DE PAULA, 2004). Sob essa visão, a aprendizagem ocorre quando uma pessoa consegue refletir sobre suas ações, reorganizando e reconstruindo suas experiências. (ANTONELLO, 2005)

Os problemas apontados por autores filiados aos estudos críticos do management são: acentuação da instrumentalidade; menor efetividade de conteúdos e métodos; excessiva redução da complexidade dos fenômenos estudados; reduzido incentivo à autonomia $e$ ao autodidatismo; 'mercadorização' do ensino (WOOD JR; PAES DE PAULA, 2004). Essa corrente salienta a necessidade de o indivíduo desenvolver visão crítica e raciocínio analítico. Antonacopoulou (2010), por exemplo, questiona a validade de modelos funcionalistas, geralmente apresentados nos programas de MBA e sugere que os participantes sejam encorajados a trazer questões oriundas de suas experiências, explorando conexões e inter-relações entre elas, desafiando e refletindo sobre suas percepções, permitindo a obtenção de insights a partir dessas experiências. Nesse sentido, a reflexão media a aprendizagem gerencial, possibilitando entender situações, aprender com os erros e críticas, avaliar alternativas, realizar escolhas - atributos essenciais para gestores. (SILVA; SILVA, 2011)

A reflexão é concebida por Schön (2000) como um processo que envolve a busca, o teste e a avaliação de entendimentos intrínsecos à experiência, à prática profissional. Duas possibilidades de responder a algum elemento surpresa em experiências rotineiras são observadas por Schön: 1) refletindo sobre a ação retrospectivamente, por meio de uma pausa para pensar no meio da ação, desconectando a reflexão da ação presente; ou 2) pela reflexão na ação, refletindo no meio da ação, pensando para dar forma ao que está sendo realizado, a fim de interferir na ação em andamento. A reflexão na ação torna-se essencial para lidar com situações problemáticas envolvidas no trabalho diário de gestores.

Cunliffe (2004) observa dois modos diferentes de, pela reflexão, dotar uma experiência de sentido. $\mathrm{O}$ primeiro é através da "análise reflexiva", uma aprendizagem instrumental que possibilita mudanças de estratégia de ação ou pressupostos sem, no entanto, modificar valores de uma teoria de ação. O segundo, o "questionamento reflexivo crítico", baseia-se no pressuposto que existem realidades construídas, múltiplas e subjetivas. Essa noção, que se assemelha à reflexão crítica, envolve a exposição de contradições, dúvidas, dilemas, possibilidades, buscando iluminar ideologias e pressupostos tácitos. Cunliffe (2009) destaca a relevância da autorreflexão, através do questionamento de crenças e de entendimentos acerca de determinados eventos e de como eles moldam as respostas dos indivíduos, processo que pode torná-los sensíveis ao outro e abertos a novas possibilidades de ser e de agir.

Embora a educação formal tenha como objetivo explícito o desencadeamento de aprendizagens, estas ocorrem igualmente na vida cotidiana das pessoas e 
nas organizações, sendo um processo multidimensional que envolve, além da dimensão técnica, a compreensão do contexto de atuação profissional que contribui para o desenvolvimento de habilidades, mudanças de perspectivas e autodesenvolvimento de gestores (SILVA, 2008). Uma visão alternativa da aprendizagem a concebe como uma prática social (GHERARDI; NICOLINI, 2001). Para se realizar, sob essa perspectiva, uma interpretação válida de uma atividade de aprendizagem, é preciso compreender o contexto específico das atividades e das práticas sociais em que ela ocorre, considerando-se o contexto como um produto histórico e social, produzido conjuntamente com as atividades que apoia (GHERARDI; NICOLINI; ODELLA, 1998). Elkjaer (2011) destaca uma perspectiva temporal das práticas sociais, na qual pessoas e situações se constroem e reconstroem continuamente através de processos experimentais e reflexivos de engajamento social.

Maclean, Harvey e Chia (2012b, p. 388) salientam a importância da prática reflexiva na carreira de altos executivos, conceituando reflexividade como a capacidade desses profissionais "[...] construírem entendimentos práticos quanto a sua posição em um sistema social, para agir em conformidade com ela, refletir e refinar entendimentos em resposta a eventos $e$ a consequências de ações empreendidas". A ação reflexiva questiona as bases do entendimento sobre determinados eventos, sobre práticas e sobre a própria vida (XING; SIMS, 2012). Maclean, Harvey e Chia (2012a) identificaram cinco modos de a reflexividade se expressar na prática: através do acúmulo de capital pessoal (recursos econômicos, culturais, sociais e simbólicos utilizados para alcançar objetivos); abarcando oportunidades; superando limitações; aprendendo a partir de adversidades; desenvolvendo estratégias pessoais.

As mudanças, na sociedade e nas organizações, renovaram o interesse de pesquisadores do campo da Administração sobre a aprendizagem informal no ambiente de trabalho. A aprendizagem informal acontece como parte das atividades cotidianas exercidas pelos indivíduos, caracterizando-se pelo controle da aprendizagem centrar-se, principalmente, no aprendiz e por ser normalmente intencional, mas não altamente estruturada, podendo ocorrer também no âmbito formal. A aprendizagem incidental está incluída na categoria da aprendizagem informal, definida como um subproduto, muitas vezes tácito ou inconsciente, da realização de atividades, de interações interpessoais, de experimentações ou mesmo da aprendizagem formal. (MARSICK; WATKINS, 2001; MARSICK, 2006)

\section{MÉTOdo: HISTÓRIA DE VIDA}

A revisão da literatura sugeriu que, ao longo dos anos, as expectativas sociais, o desenvolvimento $e$ as mudanças vivenciadas por indivíduos motivam e interagem com a aprendizagem, sendo a dimensão trabalho uma de suas principais forças interativas (MERRIAM; CAFFARELLA, 1999; DANIS; SOLAR, 2001; CLARK; CAFFARELLA, 1999; MACLEAN; HARVEY; CHIA, $2012 \mathrm{a}, \mathrm{b})$. Tal percepção conduziu à proposição de que diferentes processos de aprendizagem adquirem maior ou menor importância conforme o momento de vida, as mudanças vivenciadas, o estágio de desenvolvimento na carreira em que cada profissional se encontra. Uma vez que mudanças no contexto contemporâneo exigiram mudanças nas formas de gerir as organizações (HALLINGER; SNIDVONGS, 2008), formulou-se ainda a proposição que novas aprendizagens gerenciais decorreram de tais transformações. O passo seguinte foi a elaboração de um desenho de pesquisa que permitisse explorar tais proposições.

A compreensão de 'como' ocorrem os processos de aprendizagem considerados importantes por gestores, durante suas vidas, em meio ao contexto de transformações contemporâneas, requereu a realização de uma pesquisa qualitativa. A abordagem de história de vida foi adotada por favorecer a compreensão de diferentes processos de aprendizagem interligados, no decorrer de suas vidas (CLOSS; ANTONELLO, 2011), possibilitando a contextualização pessoal, histórica, social, institucional e política de narrativas (DENZIN, 1989), revelando ações e emoções, bem como interações entre pessoas e eventos. (XING; SIMS, 2012)

O perfil de participantes do estudo é o de profissionais com formação superior e experiência executiva (em gerência, diretoria e presidência). A experiência em gestão foi um dos critérios adotados para a escolha de profissionais oriundos de programas de MBA Executivos - perfil dos integrantes desse tipo de curso - vista a possibilidade de maior riqueza de dados para interpretação proporcionada por gestores mais experientes. Outro aspecto motivador da escolha desses participan- 
tes é o de, normalmente, ser a titulação em um curso de MBA ou de mestrado a mais alta titulação almejada por um executivo, a menos que haja interesse por uma carreira docente, o que pode levar à procura de um curso de doutorado. Nesse sentido, o perfil de gestores escolhido possibilita compreender como ocorrem seus processos de aprendizagem, após atingirem o que se pode considerar o "topo" da formação acadêmica de um executivo.

Procurou-se, na composição do grupo entrevistado, equilibrar a presença de gestores do gênero feminino e masculino, assim como buscar diversidade de vivências entre eles, compreendendo formações básicas distintas, experiências em áreas de atuação e setores diversos, realização de cursos de MBA e mestrado em instituições diferentes, além de contemplar uma faixa etária abrangente. Foram entrevistados seis gestores egressos de curso(s) de MBA executivo, realizados em programas nacionais e internacionais, bem como uma gestora egressa de um curso de mestrado realizado no exterior, indicada por um dos gestores entrevistados devido à sua experiência em gestão $e$ à sua atuação em uma empresa de alta tecnologia, setor de atuação distinto dos demais participantes. Os perfis desses profissionais estão sintetizados no Quadro 1.

\begin{tabular}{|c|c|c|c|c|c|}
\hline SujeIto & IDADE & Cargo atual & ATUAÇÃo DA EMPRESA & FoRMAÇÃo & Mestrado \\
\hline Helena & 30 & Controller Segmento & Indústria de tecnologia & Economia & Finanças Intl. Londres \\
\hline Vasco & 35 & Gerente de Planej. e MKT & Empresa de Comunicação & Economia & $\begin{array}{l}\text { MBA } \\
\text { Belo Horizonte }\end{array}$ \\
\hline Gui-lherme & 37 & Diretor de operações & Empresa de Comunicação & Administração & MBA Califórnia - USA \\
\hline João & 37 & Gerente de Planej. e MKT & Instituição Financeira & Comunicação & $\begin{array}{l}\text { MBA } \\
\text { Porto Alegre }\end{array}$ \\
\hline Ana Niza & 41 & Gerente de $\mathrm{RH}$ & $\begin{array}{l}\text { Indústria de } \\
\text { mecanização agrícola }\end{array}$ & Administração & $\begin{array}{l}\text { MBA } \\
\text { Porto Alegre }\end{array}$ \\
\hline Sofia & 45 & Sócia-proprietária & $\begin{array}{l}\text { Assessoria de mercado } \\
\text { química e petroquímica }\end{array}$ & Engenharia química & $\begin{array}{l}\text { MBA } \\
\text { Porto Alegre }\end{array}$ \\
\hline Augusto & 55 & Presidente & Instituição Financeira & $\begin{array}{l}\text { Administração } \\
\text { Contabilidade }\end{array}$ & $\begin{array}{l}\text { MBA } \\
\text { Porto Alegre }\end{array}$ \\
\hline
\end{tabular}

Quadro 1: Perfil dos gestores entrevistados

Fonte: Elaborado pelos autores deste artigo

Na primeira entrevista, solicitou-se aos gestores que discorressem livremente sobre suas trajetórias de vida, destacando experiências que lhes trouxeram aprendizagens importantes. Após a primeira entrevista e a cada nova entrevista, os relatos foram, imediata e fielmente, transcritos. Dada à falta de orientação na literatura sobre o manuseio $e$ a análise do material transcrito, estabeleceu-se uma metodologia de trabalho própria, embasada em diversos autores (DEMARTINI, 1988; QUEIROZ, 1988; DENZIN, 1989). Após a realização de leituras atentas de cada história de vida, buscando experiências e significados relevantes para cada entrevistado, foram destacados trechos das narrativas, associados aos objetivos da pesquisa, constituindo-se categorias amplas. A análise dos diversos trechos selecionados, à luz da literatura sobre o tema, possibilitou a identificação de subcategorias, envolvendo padrões de experiências e significados semelhantes, organizadas em torno das categorias que correspondiam aos objetivos específicos do estudo. Uma síntese da história de vida foi então escrita, bem como as análises interpretativas, incluindo os trechos das narrativas mais representativas das questões analisadas na íntegra.

Esse procedimento foi adotado na análise dos relatos de história de vida dos três primeiros participantes, propiciando a identificação de categorias relevantes para a compreensão da questão de pesquisa proposta pelo presente estudo. A partir do quarto entrevistado, os relatos das histórias de vida foram igualmente sintetizados, lidos e relidos atentamente, analisados e subcategorizados, conforme os anteriores, no entanto, o processo de análise dos conteúdos das narrativas foi sistematizado em mapas, inspirados no modelo proposto por Spink e Lima (2000). A construção dos 
mapas originou-se das categorizações constituídas pelos objetivos da pesquisa e das subcategorizações identificadas nas análises realizadas anteriormente. Surgiram, neste processo, novas subcategorizações e houve modificações de anteriores. Buscou-se sintetizar as informações mais importantes para o processo de análise.

Concluídas as análises individuais dos três primeiros gestores entrevistados e as análises e os mapas dos demais, o conjunto de informações foi analisado, envolvendo a identificação de semelhanças e diferenças; a redefinição de categorias; a interpretação com base nos referenciais teóricos existentes e em novos referenciais que auxiliassem a compreensão dos objetivos de pesquisa. $\mathrm{O}$ retorno aos relatos completos das histórias de vida foi recorrente, procurando-se não perder de vista a contextualização das narrativas de cada entrevistado. A Figura 1 apresenta, de maneira sintética e sistematizada, os principais procedimentos para coleta e análise dos dados.
PROCEDIMENTOS INICIAIS: As questőles para a obtençăo de uma história de vida devem variar de acordo com o entrevistado, năo sendo possivel seguir um roteiro rígido de questobes,

recomendaçăo adotada pela pesquisadora na investigaçăo realizada. A coleta de dados envolve, tipicamente, uma série de pelo menos duas ou três entrevistas de uma hora a uma hora e meia de duraçăo (Atkinson, 2002).

Considerando-se a revisăo térica realizada, solicitou-se aos participantes da pesquisa que discorressem livremente sobre suas trajetórias de vida na primeira entrevista,

destacando experiências que trouxeram aprendizagens consideradas importantes.

$$
\text { Neste momento a }
$$

pesquisadora nžo realizou

intervençб̆es, a năo ser quando

houve algum questionamento dos entrevistados.
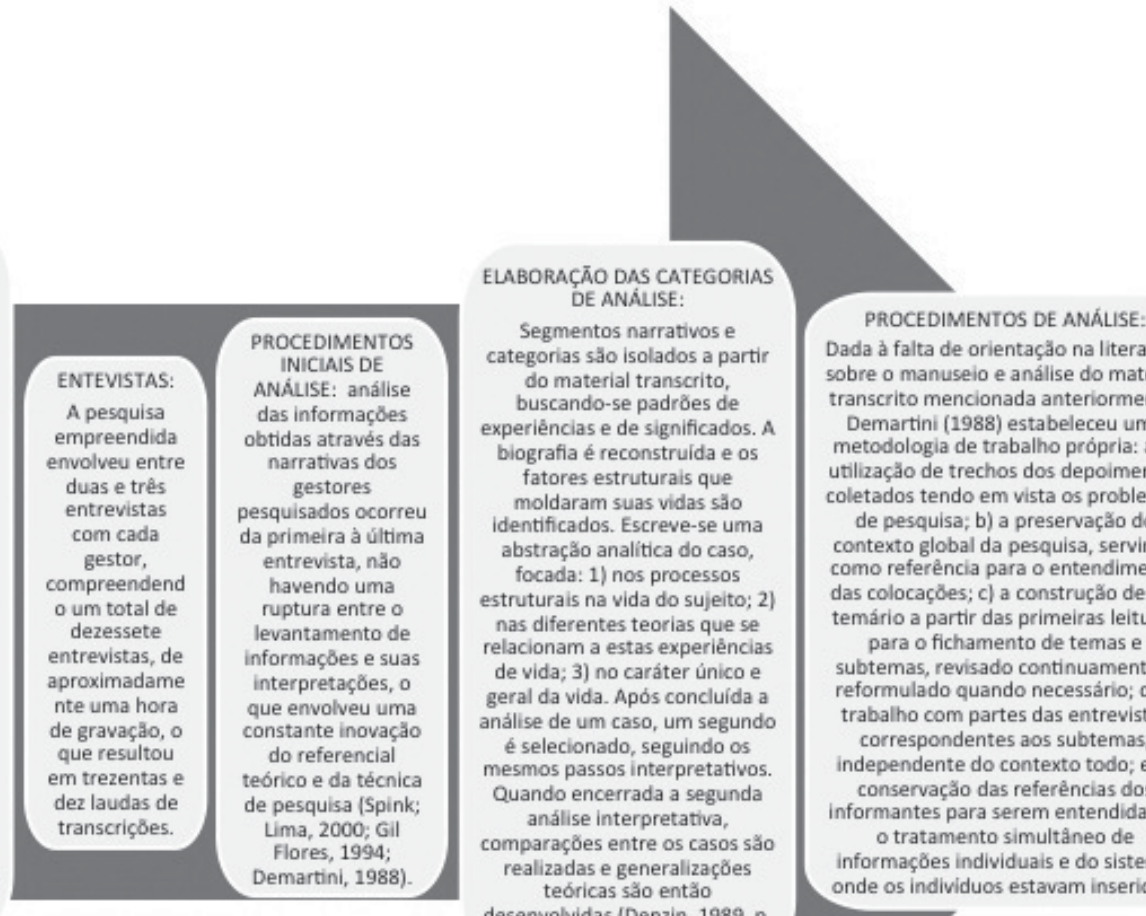

Segmentos narrativos e ategorias săo isolados a partir do material transcrito, xperiências e de significados. A

biografia é reconstruida e os fatores estruturais que moldaram suas vidas săo identificados. Escreve-se uma abstraçăo analítica do caso, focada: 1) nos processos

estruturais na vida do sujeito; 2] nas diferentes teorias que se relacionam a estas experiências de vida; 3) no caráter único e geral da vida. Após concluída a análise de um caso, um segundo

é selecionado, seguindo os mesmos passos interpretativos.

Quando encerrada a segunda análise interpretativa,

comparaçôes entre os casos săo

realizadas e generalizaçб̄es teóricas săo entăo

PROCEDIMENTOS DE ANÁLISE: Dada a falta de orientaçăo na literatura transcrito mencio e análise do material Demartini (1988) estabeleciomente, Demartini (1988) estabeleceu uma metodologia de trabalho propria: a) a utilizaçăo de trechos dos depoimentos coletados tendo em vista os problemas de pesquisa; b) a preservaçăo do contexto global da pesquisa, servindo como referência para o entendimento das colocaçð̄es; c) a construçăo de um temário a partir das primeiras leituras para o fichamento de temas e subtemas, revisado continuamente e reformulado quando necessário; d) o trabalho com partes das entrevistas correspondentes aos subtemas, independente do contexto todo; e) a conservaçăo das referências dos informantes para serem entendidas; f) o tratamento simultâneo de informaçб̄es individuais e do sistema onde os individuos estavam inseridos.
56).

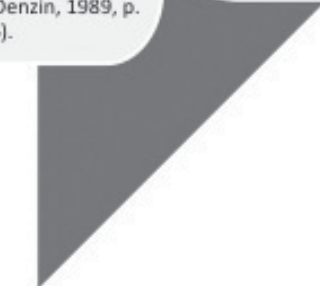

Figura 1: Síntese dos procedimentos metodológicos adotados na pesquisa

Fonte: Elaborada pelos autores deste artigo 


\section{Análise dos Dados: processos de APRENDIZAGEM SIGNIFICATIVOS AO LONGO DA VIDA PROFISSIONAL DOS GESTORES}

Confirmou-se o pressuposto de que diferentes processos de aprendizagem adquirem maior importância, em função do momento de vida e do estágio da carreira que os gestores vivenciam. Identificou-se que muitos dos comportamentos e valores dos executivos foram aprendidos na infância, com os modelos familiares. As experiências, positivas ou envolvendo a superação de limitações e adversidades (MACLEAN; HARVEY; CHIA, 2012a), constituíram ricos recursos para a aprendizagem.

As análises dos processos de aprendizagem percebidos como importantes, durante a vida dos gestores, são apresentadas agrupadas por períodos ou por eventos relatados, que encontram semelhanças em suas trajetórias e implicam processos de aprendizagem. Por questão de espaço são apresentadas, no Quadro 2 apenas, as categorias de análise identificadas a partir das primeiras experiências de profissionais dos pesquisados, discutidas nas seções subsequentes.

\begin{tabular}{|c|c|c|c|}
\hline Período de VIDA & Eventos & Processos de APRENDizagem & Aprendizados \\
\hline $\begin{array}{l}\text { Adulta: } \\
\text { primeiras } \\
\text { experiências } \\
\text { profissionais }\end{array}$ & Vivências profissionais & $\begin{array}{l}\text { Experiência } \\
\text { Informais } \\
\text { Incidentais } \\
\text { Coaching/mentoring: } \\
\text { profissional, pessoal } \\
\text { Experienciar }\end{array}$ & $\begin{array}{l}\text { Postura, convívio, valores } \\
\text { Conhecimentos: realização } \\
\text { de tarefas operacionais } \\
\text { Visão organizacional }\end{array}$ \\
\hline & & Reflexão & Adaptar-se às possibilidades \\
\hline $\begin{array}{l}\text { Transição para } \\
\text { vida adulta }\end{array}$ & $\begin{array}{l}\text { Escolha do curso } \\
\text { de graduação }\end{array}$ & Ausentes & $\begin{array}{l}\text { Necessidade de aprender durante } \\
\text { o curso, mudança de curso ou } \\
\text { redirecionamento profissional. }\end{array}$ \\
\hline \multirow{6}{*}{$\begin{array}{l}\text { Adulta: } \\
\text { desenvolvimento } \\
\text { e vivência } \\
\text { profissional }\end{array}$} & $\begin{array}{l}\text { Busca de especialização } \\
\text { profissional e retorno } \\
\text { aos estudos (mestrado; } \\
\text { especialização; } \\
\text { outra graduação) }\end{array}$ & $\begin{array}{l}\text { - Autodirecionamento } \\
\text { (necessidade de aprender para } \\
\text { executar funções; se diferenciar); } \\
\text { - Informais; } \\
\text { - Incidentais. }\end{array}$ & $\begin{array}{l}\text { - Conhecimentos teóricos } \\
\text { aprofundados (mestrado) } \\
\text { - Conhecimentos instrumentais para aplicar } \\
\text { no trabalho (especialização, } 2^{a} \text { graduação) } \\
\text { - Conhecimentos específicos; adquiridos } \\
\text { na empresa; dicas de colegas }\end{array}$ \\
\hline & Realização de um MBA & $\begin{array}{l}\text { - Leitura } \\
\text { - Realização da dissertação, pesquisa } \\
\text { - Interação com colegas } \\
\text { e professores } \\
\text { - Convívio com diversidade }\end{array}$ & $\begin{array}{l}\text { - Percepção da subjetividade } \\
\text { - Visão sistêmica } \\
\text { - Conhecimentos aplicáveis, } \\
\text { em áreas específicas } \\
\text { - Importância do network } \\
\text { - Idioma, conhecimento de } \\
\text { outras culturas (no exterior) }\end{array}$ \\
\hline & Atuação como professor & $\begin{array}{l}\text { - Leituras, estudo } \\
\text { - Relação de estudos } \\
\text { com experiências } \\
\text { - Interação com alunos e } \\
\text { outros professores } \\
\text { - Reflexão } \\
\text { - Autodirecionamento }\end{array}$ & $\begin{array}{l}\text { - Insights sobre prática profissional } \\
\text { - Preparo de aulas, formas de } \\
\text { atuar em sala de aula } \\
\text { - Conhecimentos } \\
\text { - Falar em público }\end{array}$ \\
\hline & \multirow{3}{*}{$\begin{array}{l}\text { Empresa como escola: } \\
\text { cultura, modelos, o } \\
\text { que e como aprender }\end{array}$} & $\begin{array}{l}\text { - Informal: assimilação da } \\
\text { cultura organizacional } \\
\text { - Observação de modelos }\end{array}$ & - Valores \\
\hline & & $\begin{array}{l}\text { - Formal: treinamentos na empresa; } \\
\text { cursos financiados pela empresa } \\
\text { - Informal: gestores, pares }\end{array}$ & $\begin{array}{l}\text { - Modelos de gestão } \\
\text { - Conhecimentos e habilidades }\end{array}$ \\
\hline & & $\begin{array}{l}\text { - Processo de avaliação: } \\
\text { planos de desenvolvimento }\end{array}$ & $\begin{array}{l}\text { - Autoconhecimento } \\
\text { - Necessidades de aprendizagens }\end{array}$ \\
\hline
\end{tabular}




\begin{tabular}{|c|c|c|c|}
\hline Período de VIDA & Eventos & Processos de APRENDIZAGEM & ApRendizados \\
\hline \multirow{5}{*}{$\begin{array}{l}\text { Adulta: } \\
\text { desenvolvimento } \\
\text { e vivência } \\
\text { profissional }\end{array}$} & $\begin{array}{l}\text { Novos papéis, } \\
\text { responsabilidades, } \\
\text { projetos e desafios }\end{array}$ & $\begin{array}{l}\text { - Interagir com pessoas } \\
\text { - Reflexão-na-ação } \\
\text { - Análise reflexiva } \\
\text { - Participação em projetos } \\
\text { - Transferência de expertises } \\
\text { - Expondo-se } \\
\text { - Praticando }\end{array}$ & $\begin{array}{l}\text { - Postura, convívio } \\
\text { - Proposição de melhorias } \\
\text { - Ter que surpreender } \\
\text { - Complexidade da gestão, responsabilidade } \\
\text { do gestor, visão generalista } \\
\text { - Empatia, habilidades de relacionamento }\end{array}$ \\
\hline & $\begin{array}{l}\text { Reflexão sobre } \\
\text { dificuldades e frustrações }\end{array}$ & - Reflexão/Análise reflexiva & $\begin{array}{l}\text { - Priorização de coisas } \\
\text { - Readequar expectativas } \\
\text { - Prever novas situações } \\
\text { - Percepção de aspectos intangíveis }\end{array}$ \\
\hline & $\begin{array}{l}\text { Experiência profissional: } \\
\text { "tempo de janela" }\end{array}$ & $\begin{array}{l}\text { - Experiencial } \\
\text { - Reflexividade }\end{array}$ & $\begin{array}{l}\text { - Integração de saberes } \\
\text { - Enfrentar situações com mais facilidade } \\
\text { - Interação com pessoas } \\
\text { - Capacitação para atuar em } \\
\text { sua área profissional } \\
\text { - Conhecimento de uma prática }\end{array}$ \\
\hline & $\begin{array}{l}\text { Integrando a } \\
\text { subjetividade: além } \\
\text { da racionalidade }\end{array}$ & $\begin{array}{l}\text { - Reflexão } \\
\text { - Integrando intuição } \\
\text { - Integrando a emoção }\end{array}$ & $\begin{array}{l}\text { - Compreensão de situações } \\
\text { envolvendo emoções } \\
\text { - Visão da desconsideração das } \\
\text { pessoas pelas empresas } \\
\text { - Como lidar com pessoas }\end{array}$ \\
\hline & $\begin{array}{l}\text { Filhos e viagens: } \\
\text { mudanças de esquemas } \\
\text { de significados. }\end{array}$ & $\begin{array}{l}\text { - Mudanças de esquemas de } \\
\text { significado: psicológicas; } \\
\text { Sociolingüísticas }\end{array}$ & $\begin{array}{l}\text { - Descentração, novas prioridades, } \\
\text { conciliação do tempo com outros } \\
\text { papéis, responsabilidade } \\
\text { - Compreensão de culturas, de } \\
\text { valores, novas perspectivas }\end{array}$ \\
\hline
\end{tabular}

Quadro 2: Processos de aprendizagem significativos envolvendo desenvolvimento e vivência profissional Fonte: Elaborado pelos autores deste artigo

\subsection{Escolha por Curso de Graduação e a Vivência Profissional Inicial}

Um aspecto muito significativo para os entrevistados, no período de transição para a vida adulta, foi a necessidade de direcionamento profissional, marcada pelo rito de passagem de aprovação no vestibular e pelo ingresso em uma faculdade - um caminho natural para eles, já que, no Brasil, a educação formal obtida no bacharelado é pré-requisito para projetar um futuro profissional promissor. A escolha do curso de graduação, entretanto, não foi fácil para a maioria dos gestores. Em geral, ela não ocorreu como fruto de conhecimentos profundos ou de experiências sobre as áreas de atuação, aliados a autoconhecimento, aprendizagens que auxiliariam a seleção de uma faculdade ou área de atuação. Sofia, por exemplo, optou por Engenharia Química, entre outros fatores, pelo desafio que o curso - difícil em sua época - representava. Para Augusto, a opção se deu entre oportunidades alternativas à primeira escolha e constituiu-se a partir de um processo de aprendizagem, envolvendo insights sobre suas limitações e a formulação de estratégias de ação para superá-las:

[...] eu havia tentado uma faculdade de agronomia, [...] mas eu não fui feliz no vestibular e não consegui passar, na UFRGS. E também não tinha condições de fazer cursinho $e[\ldots]$ decidi mudar de rumo. Foi então que [...] pois bem, vamos fazer o que é possível. E o que era possível era uma faculdade de economia lá da região, em Bento Gonçalves. Fiz um ano e meio, acho que... três semestres e aí é que eu decidi ir a São Paulo buscar oportunidades [...] decidi continuar os meus estudos em São Paulo [...]

A carreira em gestão não foi premeditada pela maioria dos entrevistados, tendo sido, muitas vezes, motivada pela busca por bons rendimentos e por oportunidades surgidas de suas primeiras experiências profissionais. Eles acolheram as oportunidades profissionais que o mercado disponibilizou em está- 
gios ou em empregos bastante operacionais, entre os primeiros semestres e o meio do curso de graduação. Seus objetivos eram, então, se sustentarem, adquirirem alguma experiência de trabalho e melhor entenderem sua profissão, não havendo muitas possibilidades de fazerem escolhas no início da carreira.

A maioria dos aprendizados relatados pelos entrevistados adveio, neste período inicial, da busca por conhecimentos técnicos e da realização de tarefas operacionais, no dia a dia do trabalho, caracterizando processos de aprendizagem de caráter informal, não estruturados. Aprendizagens incidentais foram também observadas como um subproduto, muitas vezes tácito ou inconsciente, tanto da realização de tarefas quanto da interação interpessoal, de experimentações ou da aprendizagem formal. (MARSICK, 2006)

Huberman (1992) identifica "maxiciclos" que permeiam a carreira tanto de diferentes indivíduos, exercendo a mesma profissão, como a de pessoas em distintas carreiras. As primeiras experiências profissionais dos gestores encontram semelhanças no ciclo que o autor denomina "exploração", o qual envolve uma opção provisória, uma primeira investigação da profissão, quando os indivíduos experimentam um ou mais papéis, aspectos observados nos relatos dos pesquisados. Novos movimentos "exploratórios", no entanto, são observados em suas trajetórias, devido a mudanças de atividades e setores de atuação.

\subsection{Desenvolvimento e Vivência Profissional}

Na busca por desenvolvimento de carreira, percebeu-se a procura por grandes empresas, que sinalizam possibilidades de crescimento profissional e melhores remunerações. Para alcançar este propósito, novos investimentos em educação foram realizados, em cursos de pós-graduação, motivados pela necessidade de desenvolver uma área de expertise e preencher lacunas deixadas pelos cursos de graduação. Formado em Comunicação e atuando na área de marketing, em atividades bem operacionais, João fez um curso de pós-graduação nesta área, o qual, além de proporcionar conhecimentos, representou a possibilidade de buscar, no mercado, melhores oportunidades. Ana Niza teve poucas disciplinas em Recursos Humanos, no curso de Administração, por isso, fez um curso de pós-graduação, quando iniciou a trabalhar nesta área. Embora o objetivo principal tenha sido adquirir conhecimentos de caráter instrumental, eles se confrontaram, neste percurso, com situações que lhes trouxeram uma série de outras aprendizagens, especialmente de caráter incidental.

Após concluírem seus cursos de pós-graduação e começarem a atuar em uma área específica, os gestores buscaram, em geral, crescimento na carreira $e$ condições de trabalho satisfatórias, assumindo cargos com maior responsabilidade, prestígio e remuneração. A busca por manterem seus empregos/negócios, pelo desenvolvimento e crescimento profissional, foi contínua nas carreiras dos entrevistados, reforçando a necessidade de aprendizagem ao longo da vida. A diferenciação profissional, igualmente importante para a atuação dos gestores no contexto atual, torna o aprendizado mais automotivado e voluntário (ORVIS; RATWANI, 2010), os gestores assumem maior responsabilidade primária pelo planejamento, pela condução e pela avaliação do próprio aprendizado, características das aprendizagens autodirigidas. (KNOWLES, 1975)

A maioria dos gestores entrevistados partiu para a realização de um MBA, quando já possuía experiências de trabalho sólidas e um crescimento profissional que lhes possibilitava serem financiados por suas empresas ou arcarem com o pagamento destes cursos. Entre suas motivações comuns, estava o desejo de qualificação $e$ de reconhecimento no meio empresarial, além de perspectivas de maiores remunerações e crescimento, corroborando a visão de que os programas de MBA se apresentam como uma via para ganhar competitividade no mercado profissional (WOOD JR; PAES DE PAULA, 2004; ANTONACOPOULOU, 2010). Os aprendizados adquiridos no MBA envolveram processos de aprendizagem formais e informais, não havendo uma fronteira entre esses processos que ocorrem de forma interligada. Os relacionamentos no MBA foram importantes para João, proporcionando a ele duas novas colocações profissionais. Vasco ressaltou também a interação com pessoas de empresas grandes, multinacionais - a network desenvolvida - afora os aprendizados com os professores.

Apenas João e Helena atuaram como professores, mas ambos destacaram esta experiência como uma das mais significativas em termos de aprendizagem. O encontro com a diversidade na interação com os alunos e as questões imprevistas favorecem, segundo 
eles, o processo de aprendizagem reflexivo (CUNLIFFE, 2004, 2009). O contínuo autodesenvolvimento se dá na busca constante por novos conhecimentos e por novas formas de atuar em sala de aula.

Ana Niza, João e Guilherme consideraram como uma segunda escola sua experiência profissional em empresas de grande porte, com estrutura, ferramentas e processos modernos. A relevância dos modelos de gestão e de ferramentas aprendidos nestas organizações, seja de modo formal, em treinamentos, seja de modo informal, com lideranças, pares e nas vivências do dia a dia, foi enfatizada por eles. João destacou que a reaplicação de seus conhecimentos adquiridos nestas organizações foi muito valorizada em empresas de pequeno porte, menos estruturadas. Aspectos culturais das organizações em que os gestores trabalharam foram também aprendidos e marcantes, tais como a valorização do enfrentamento de desafios, em uma das primeiras organizações em que João trabalhou, uma empresa multinacional:

[...] estava presente na atitude das pessoas. Então, era até feio a gente negar um desafio, sério, sabe? Aquela coisa de reunião, assim, era até constrangedor a pessoa ficar achando: "ah, mas eu não sei se eu tenho condição" [...] Logo viria um comentário do tipo: "como não tem condição? O que tu estás fazendo aqui? [...] tu achas que tu estás trabalhando ali na tabacaria da esquina?" Então, ninguém disse que era pra ser assim, mas isso tava dentro do DNA da empresa.

Facetas da cultura de determinado grupo ou organização permeiam as práticas sociais das empresas. Indivíduos e grupos constroem o sentido de suas ações e eventos, considerando sua autoria $e$ a negociação mútua das narrativas (MACLEAN; HARVEI; CHIA, 2012a). Embora a cultura organizacional seja condição essencial para promover e apoiar a aprendizagem nas organizações, há uma lacuna na literatura sobre este tema. (REBELO, 2011)

Percebeu-se também a influência da organização na disponibilização de recursos e no direcionamento do quê e do como aprender (ANTONACOPOULOU, 2006; SILVA, 2008), assim como a influência das trajetórias dos executivos do alto escalão da empresa, como guias de comportamentos para os demais profissionais (MERRIAM; CAFFARELLA, 1999). No escalão executi- vo do grupo no qual Guilherme e Vasco trabalham, por exemplo, os 'heróis' da organização realizaram cursos de MBA no exterior, pagos pela empresa. Guilherme aproveitou esta oportunidade e estudou na Califórnia. Vasco não teve esta possibilidade, pois, recentemente, a empresa deixou de financiar a realização de MBAs no exterior. Ele estudou, então, em uma instituição de ensino reconhecida em âmbito nacional, mas seu sonho de estudar no exterior permanecia.

Outro fator que influencia a busca de aprendizados pelos gestores são os planos de desenvolvimento profissional, criados por algumas grandes empresas, tais como aquelas em que trabalhavam Vasco, Guilherme, Helena e Ana Niza. Os pontos de desenvolvimento dos executivos estão ligados ao modelo de gestão das organizações e expressam competências desejadas para cada cargo. Algumas das competências esperadas de gestores na empresa em que trabalhavam Vasco e Guilherme, por exemplo, eram: visão estratégica, orientação para resultados, liderança de pessoas, capacidade de influenciar, além de networking, aspecto também destacado por João e Sofia. Isso denota o isomorfismo institucional, o qual encoraja a imitação de atitudes gerenciais em diferentes setores de atuação. (ANTONACOPOULOU, 2006)

O início em qualquer novo emprego ou nova situação de trabalho é um período muito marcante e de muitos aprendizados para todos os gestores entrevistados. Segundo Helena,

[...] o início, as primeiras atividades profissionais, diria assim, primeiro emprego, primeira entrevista, acho que isso é muito marcante. A gente aprende bastante nesse processo, assim, de começar a se colocar, de começar a interagir profissionalmente. [...] Acho que isso foi bem marcante. Na verdade, é marcante a cada novo emprego, a cada nova situação que a gente sempre - são fases, assim, que marcam muito. São de consumo de muita energia

A participação em novos projetos empresariais, que oportunizam a criação de coisas novas, foi destacada por Vasco, Helena e João como experiências muito gratificantes. "Abraçar oportunidades" (MACLEAN; HARVEY; CHIA, 2012b) e experiências que trazem possibilidades de desenvolvimento de novas ideias ou abordagens, além de estimulantes, são ricas fontes de aprendizado. (ANTONELLO, 2004) 
Guilherme salientou que aprendeu muito convivendo com uma consultoria estratégica, que ampliou suas perspectivas profissionais e possibilitou que entendesse o pensamento do acionista e do negócio, da indústria, e não apenas da empresa na qual atuava. Arthur, DeFillippi e Jones (2001) assinalam as oportunidades de aprendizagem propiciadas pela participação em projetos, na interação entre integrantes da empresa e membros externos.

Ana Niza relatou que seu maior aprendizado profissional ocorreu ao assumir uma posição gerencial em uma nova empresa, em São Paulo, na qual teve que "fazer de tudo", desde contratar o vigilante a coordenar, pela primeira vez, uma pequena equipe. Assim, obteve uma visão generalista da área de Recursos Humanos que permite que trafegue em todas as suas funções com conhecimento, facilitando, pois, sua trajetória. Ao assumir cargos gerenciais, um dos aprendizados ainda assinalados pelos gestores é a importância de habilidades de relacionamento interpessoal para a gestão de pessoas. Vasco, por exemplo, enfatizou a importância da empatia para gerenciar equipes, aspecto que aprendeu praticando, em um processo de autodesenvolvimento. (ORVIS; RATWANI, 2010)

Percebe-se que assumir novos desafios e atividades expõe os profissionais a uma série de situações que demandam processos de aprendizagem (MACLEAN; HARVEY; CHIA, 2012b). Essas aprendizagens contribuem para seu desenvolvimento profissional, favorecendo, frequentemente, o surgimento de novas oportunidades profissionais e desafios que conduzem, por sua vez, a novas aprendizagens.

Segundo Merriam e Caffarella (1999), mais aprendizagens ocorrem em momentos de vida considerados bons, mas os significados mais profundos dos eventos são extraídos de momentos difíceis. Tal como observam as autoras, a maioria dos gestores entrevistados destacou que as reflexões geradas por dificuldades e frustrações, envolvendo fortes emoções, tanto no plano pessoal como profissional, foram possivelmente os mais importantes catalisadores de suas aprendizagens. Conforme João:

É duro admitir, mas é na dificuldade, são os desafios mais duros, assim, mais difíceis, as coisas mais "cabulosas" que realmente saem os aprendizados mais... importantes. Não é só porque marca a gente, é porque aquilo tem uma riqueza de material, dos fatos, tem uma riqueza de análise, assim, que uma situação de acerto muitas vezes, de êxito, a gente não consegue medir com tanta clareza [...]

Ressalta-se, nesse sentido, a importância da análise reflexiva (CUNLIFFE, 2004, 2009), um processo que envolve a reflexão sobre experiências passadas para transformá-las em compreensões mais profundas, integrando tanto intelecto quanto sentidos e sentimentos. Os processos de aprendizagem oriundos de desafios e experiências consideradas positivas, neste estudo, envolveram principalmente processos de reflexão na ação, enquanto os momentos difíceis envolveram predominantemente processos de reflexão após a ação. (SCHON, 2000)

As aprendizagens acumuladas, adquiridas nas vivências do dia a dia de trabalho, incluindo os bons e os maus momentos, foram muito valorizadas por todos os gestores. A natureza prática do aprendizado, mediante a interação entre indivíduo e meio ambiente, envolve experiências concretas, ação e reflexão (ANTONELLO, 2005; MACLEAN; HARVEY; CHIA, 2012b). Conforme Ana Niza:

[...] como é importante ter tempo de janela, né? Esse negócio de realmente valorizar a experiência e tal, faz a diferença na hora de tu enfrentares situações de pressão, faz diferença tu teres passado por situações semelhantes ou iguais, né, pra ti poder achar solução.

Segundo Hrimech (2001), experts em sua área desenvolvem uma organização do saber com o acúmulo de experiências concretas, na prática, formulando modelos ou esquemas mentais que integram saberes, estes constituídos por uma rede de inter-relações entre sujeitos, contextos e acontecimentos. Estes esquemas são dinâmicos e suas hipóteses são submetidas à realidade constantemente, eles se desenvolvem quando os indivíduos se defrontam com novas situações e aplicam seus saberes, um diálogo entre conhecimento e experiência que auxilia o desenvolvimento dos profissionais, à medida que se acumulam experiências.

Embora pouco destacados no meio organizacional, termos como intuição, feeling, instinto, emoção ou percepção estiveram muito presentes nas falas dos gestores pesquisados, denotando a importância da 
subjetividade no âmbito empresarial. A fala de Sofia ilustra este aspecto:

\begin{abstract}
A gente foi aprendendo como fazer e fazendo meio que no instinto. Para mim sempre foi muito no instinto mesmo, de como lidar com as pessoas, de respeitar elas, de considerar que as pessoas são diferentes umas das outras. [...] uma série de coisas que eu fui aprendendo que não tem escola.
\end{abstract}

Este aprendizado, 'no instinto' de Sofia, integra valores pessoais, adquiridos desde a infância, aos aprendizados obtidos durante suas experiências profissionais. Tais aprendizados podem ser associados à reflexão na ação (SCHON, 2000), um processo analítico objetivo pelo qual se constrói o entendimento de uma situação pelo teste de entendimentos intuitivos sobre um fenômeno vivenciado.

Os entrevistados, em sua maioria, são casados e têm filhos, com exceção de Ana Niza. Sofia e Helena optaram por engravidar após atingir alguns objetivos de carreira, sabendo da dificuldade em conciliar a vida profissional com a pessoal. A chegada dos filhos, especialmente para as gestoras, foi um momento marcante percebido nas análises das narrativas e que gerou uma aprendizagem transformadora, processo que envolve mudanças de expectativas, crenças e sentimentos. (MEZIROW, 1994)

A inclusão de um novo papel em suas vidas, o de pai ou mãe, envolveu descentrar o foco de si mesmos. Ao assumir a responsabilidade por prover sustento, por um lado, a importância dos rendimentos proporcionados pelo trabalho aumenta, fazendo com que Guilherme, por exemplo, estivesse menos disposto a assumir riscos profissionais do que estaria caso fosse solteiro $e$ não tivesse filhos. Por outro lado, os filhos demandam atenção, afeto, educação, entre outros aspectos mencionados pelos gestores, o que requer disponibilidade de tempo, escasso para a maioria dos entrevistados. Isto gera sentimentos de culpa e esforços para tentar conciliar estas esferas, exigindo novas aprendizagens.

Concluindo esta seção, destaca-se a fala de Vasco, que sintetiza a visão dos gestores sobre as aprendizagens marcantes, ao longo de suas vidas, expressando os diversos entrelaçamentos existentes em suas histórias e em suas vidas, bem como entre seus processos de aprendizagem e de desenvolvimento, tanto profissionais como pessoais:
[...] eu contei varias histórias paralelas, mas eu vejo que cada uma delas tem um papel muito importante no aprendizado. [...] As pessoas veem como desenvolvimento, curso em sala de aula e não é isso. Desenvolvimento é treinamento de mão de obra, é curso em sala de aula, é exposição a situações novas, é rodízio de função, é ler, viajar, é conversar com pessoas diferentes [...] se tu botar isso tudo dentro do caldeirão, dá um negócio legal, dá uma pessoa mais rica [...] a educação formal é muito importante, mas as outras são também, tanto quanto... Essa é a minha visão de aprendizado, de crescimento, de desenvolvimento da pessoa.

\subsection{Análises: transformações contemporâneas no mundo do trabalho e implicações em aprendizagens}

Transformações ocorridas, no contexto contemporâneo, sobretudo a partir dos anos de 1990, trouxeram uma série de implicações para a gestão das organizações. Algumas dessas transformações, percebidas pelos gestores participantes deste estudo, e suas implicações em termos de aprendizagens, estão, a seguir, sintetizadas, devido à limitação de espaço do artigo.

Em função do fluxo para os grandes centros econômicos, das necessidades de viagens e de mobilidade decorrentes da globalização, seja para a realização de cursos, seja a trabalho ou a lazer, os gestores adquiriram uma série de aprendizagens formais, informais e incidentais. O domínio do idioma inglês; o entendimento e a aceitação de outros valores; a compreensão de semelhanças e diferenças organizacionais em contextos culturais distintos; a importância de estar conectado a outros mercados; a necessidade de desenvolver novos arranjos familiares foram aprendizados decorrentes do contexto de mercado global destacados pelos gestores.

As transformações políticas, econômicas e sociais no Brasil, inserido no contexto global, influenciaram as carreiras dos gestores estudados e envolveram novas aprendizagens. Entre elas estão: o conhecimento de novas técnicas e modismos gerenciais, incorporados a seus discursos e às suas práticas gerenciais; a adaptação a novas situações profissionais, com aquisição contínua de novos conhecimentos, decorrentes de mudanças de trabalho, oportunidades e barreiras apresentadas 
pelo mercado; o autoconhecimento, oriundo de reflexões sobre potencialidades e limitações para atuar em diferentes posições profissionais; a criação e síntese de novas ideias, habilidades demandadas por uma sociedade complexa e em rápida mudança.

As novas tecnologias permitem maior velocidade $e$ acesso a informações, mas exigem também seu processamento, levando os gestores a aprenderem a filtrá -las e priorizá-las. As tecnologias móveis, como novas formas de controle e pressão organizacional, tornam necessário aprender a estabelecer limites entre vida pessoal, familiar e profissional. Em contrapartida, propiciam maior flexibilidade, favorecendo a proximidade com os filhos, bem como a redução de seu estigma de problema entre as mulheres. Percebeu-se a necessidade de identificação constante de ameaças e oportunidades ligadas ao uso de novas tecnologias, bem como de aprender a se adaptar a uma "nova lógica", dosando o uso de novas tecnologias, tanto no acesso a informações como na comunicação interpessoal, impedindo a superficialidade em ambas as situações e lidando com suas vantagens e desvantagens.

Ao contrário das gerações anteriores, que queriam maior liberdade e se opunham à rigidez das normas de sua educação, a geração atual precisa aprender a conviver com a incerteza e a busca e, com a educação, obter maior estabilidade. Os gestores procuraram melhorar seu desempenho e superar-se; acumular atividades profissionais e de desenvolvimento; lidar com desafios, pressões e responsabilidades crescentes para se manterem em seus cargos; crescerem na carreira e acumularem recursos para um futuro sem garantias. Paradoxalmente, um aprendizado importante, neste contexto, foi o de não transmitir indecisão, tomando decisões rapidamente. Para tanto, tendem a confiar mais em processos intuitivos, capazes de integrar, de modo súbito, saberes armazenados, decorrentes de experiências e aprendizagens anteriores, apropriados para atuar quando existem poucos precedentes ou várias alternativas plausíveis de solução para determinada situação. (KHATRI; NG, 2000)

A mobilidade no(s) emprego(s) tende a tornar-se constante e necessária para o crescimento na carreira, que perfaz um ziguezague entre diferentes funções e empresas, não apenas de modo ascendente. Ao assumirem novos desafios, os gestores aprenderam novas atividades e comportamentos, adquiriram visões mais generalistas e diferentes perspectivas. Além de abertura para novos aprendizados, estas mudanças exigiram: capacidade de adaptação; acúmulo de atividades e maior dispêndio de energia; gerenciamento de várias coisas ao mesmo tempo; desenvolvimento de networks; conciliação do tempo entre as atividades profissionais e pessoais/familiares. A ansiedade por crescimento profissional rápido, presente nos relatos dos pesquisados, pode estar associada à percepção da valorização da juventude e da desvalorização da maturidade no mercado de trabalho. Os executivos aprenderam ainda a traçar alternativas de trabalho e a se capacitar para enfrentar suas aposentadorias.

Com a maior participação das mulheres no mercado de trabalho, ambos os gêneros pesquisados perceberam a necessidade de quebras de paradigmas e preconceitos. Algumas gestoras relataram que precisaram aprender a se proteger, dando-se conta de barreiras encontradas ao atuarem em um reduto, ainda hoje, predominantemente masculino. Aprender a conciliar as responsabilidades profissionais com papéis pessoais e familiares é outro desafio para elas, que ainda assumem primariamente os cuidados com a casa $e$ os filhos.

Embora a maioria dos gestores aborde temáticas relacionadas à responsabilidade social e ambiental, percebe-se este enfoque mais presente no discurso do que em ações práticas. Realizar um trabalho voluntário é expresso como um objetivo futuro, pois o tempo dos executivos é escasso até para se dedicarem a questões pessoais e familiares.

\section{Considerações Finais}

No estudo realizado, percebe-se que o processo de maturação psicossocial associou-se a eventos e períodos que geraram processos de aprendizagens considerados marcantes na vida dos gestores. Assim, confirma-se a formulação inicial de que diferentes processos de aprendizagem de gestores, inseridos em um contexto com expectativas sociais que se assemelham, relacionam-se a seus estágios de vida e de desenvolvimento na carreira, bem como às mudanças e experiências vivenciadas por cada um deles. (MERRIAM; CAFFARELLA, 1999; DANIS; SOLAR, 2001; CLARK; CAFFARELLA, 1999; MACLEAN; HARVEY; CHIA, 2012 a, b) 
Verificaram-se, também, novas aprendizagens gerenciais decorrentes de transformações contemporâneas, destacando-se algumas carências, sobretudo no que tange a qualidades humanas como relações interpessoais - saber trabalhar coletivamente; ter intuição; saber se comunicar; ter estabilidade emocional - que exigem constantes autoexames, autocríticas e aprendizagens. O uso da abordagem de história de vida favoreceu a visualização da relação dinâmica existente entre os processos de desenvolvimento e de aprendizagem em suas trajetórias, permitindo considerar aprendizagens envolvendo conteúdos complexos e interligados, em situações inseridas em um contexto real. (DANIS; SOLAR, 2001)

Embora o desenvolvimento de competências sociais seja atualmente preconizado no mundo do trabalho (ANTONACOPOULOU, 2010), observou-se, no presente estudo, que é neste campo subjetivo que se encontram os maiores desafios, em termos de aprendizagens, relatados pelos pesquisados. Tais desafios envolvem o desenvolvimento de competências relacionadas ao próprio indivíduo, bem como ao indivíduo e suas interações, compreendendo a necessidade de transmitir autoconfiança e segurança, além de feeling, sensibilidade e intuição para que possam perceber mudanças e fazer "previsões" para o futuro, buscando se anteciparem em suas ações a fim de não "ficarem para trás", em meio às transformações vivenciadas.

Os discursos professados na sociedade atual são contraditórios, de acordo com os gestores. Por um lado, há supervalorização do econômico, conduzindo os profissionais à busca incessante por capacitação, que acene com possibilidades de manutenção de seus empregos e de crescimento profissional, $e$ à acumulação de bens que representam a promessa de uma vida mais feliz e de um futuro mais seguro. Por outro lado, em meio a crises éticas, sociais e ambientais, a sociedade começa a valorizar também discursos tais como o da responsabilidade social corporativa, já que as empresas estão diretamente envolvidas em muitas destas problemáticas. Sugerem-se, portanto, novos estudos para ampliar a compreensão do papel da cultura e das mudanças socioculturais na sociedade, envolvendo estes paradoxos. (HALLINGER; SNIDVONGS, 2008)

Ressalva-se ainda que, mesmo expressando com sucesso o discurso aprendido em um programa educacional, para sobreviver em vários contextos de suas vidas, os indivíduos podem incorporar o script das pessoas no poder, mantendo muitas das perspectivas contraditórias. Desse modo, destaca-se que aprendizagens transformadoras não podem ocorrer de modo individual, em meio a pressões sociais e corporativas contrárias, mas como um processo de transformação coletiva, compartilhado por outros, em meio a mudanças sociais e culturais tais como as observadas no estudo. (CUNLIFFE, 2009)

Verificou-se ainda a multidimensionalidade dos processos de aprendizagem gerenciais ocorridos de modo formal e informal (SILVA, 2008). As aprendizagens obtidas em uma dimensão da vida dos gestores perpassaram as demais, tanto em aspectos positivos como negativos. Valores adquiridos na infância mostraram-se presentes em suas vidas adultas, os auxiliando profissionalmente, quando alinhados aos valores das organizações nas quais atuaram. Valores e técnicas aprendidos no âmbito organizacional foram, por outro lado, introduzidos em suas vidas pessoais e familiares. Alguns dos valores e pressupostos adquiridos em suas trajetórias podem, no entanto, representar barreiras que limitam suas visões a respeito do mundo e de si próprios, impedindo novas possibilidades de ação em consonância com as próprias ideias, processo que pode ser favorecido pela reflexão crítica (MEZIROW, 1994), pouco evidenciada em seus relatos.

Ao serem impelidos a assumirem novos papéis, responsabilidades, projetos e desafios profissionais, em um contexto em constante mudança, aprendizagens envolvendo questionamentos, experimentação e solução de problemas, encontros e conversas informais para desenvolver suas expertises fazem-se cada vez mais necessárias, destacando-se a importância de aprendizagens de caráter autodirigido. (CRANTON, 2006; KNOWLES, 1975; ORVIS; RATWANI, 2010)

Muitas das aprendizagens significativas para os gestores ocorreram no sentido de acumular e integrar novos saberes, savoir-faire e atitudes em visões sistêmicas, mais amplas e inclusivas, favorecendo as soluções para os problemas complexos enfrentados. Isso reflete um esforço para a superação do predomínio de uma lógica racional, que fragmenta saberes, presente no atual contexto (MORIN, 2003). Dicotomias expressas entre vida profissional e familiar ou entre razão e emoção representam, no entanto, a compartimentação de dimensões indissociáveis nos seres humanos, por isso, 
o equilíbrio entre as esferas de vida pessoal, familiar $e$ profissional está em meio aos aprendizados mais difíceis, porém mais almejados. Este aspecto aproxima-se de alguns resultados obtidos em estudos desenvolvidos por D'Amico e Monteiro (2012) e Rabia e Christopoulos (2008), os quais permitem levantar reflexões acerca da relação trabalho e vida pessoal. Um dado bastante relevante, obtido nestes estudos, evidencia que os entrevistados trabalham além de 40 horas semanais (83\% dos pesquisados chega a ultrapassar 50 horas por semana), revelando carga excessiva de trabalho em detrimento da vida pessoal, familiar e do lazer, no entanto os gestores revelam obter maior satisfação no ambiente em que vivem (conforto $e$ bens materiais) e menor satisfação nas relações pessoais, familiares.

A partir deste estudo, é possível dizer que os gestores, ao enfrentarem novas situações e desafios, terminam utilizando-se de experiências e aprendizados anteriores para agir, planejarem-se e decidirem. $\mathrm{O}$ ciclo virtuoso, que se estabelece vivenciar/aprender e seu desenvolvimento profissional e de suas competências, sugere estar mais vinculado à riqueza $e$ à variedade das experiências vividas, a seu poder de reflexão e à concepção de conceitos do que ao tempo de atuação em determinada área ou empresa, por exemplo. Este resultado confirma o que Cardoso (2009) e Winterton e Winterton (1999) observaram, quando expressaram

[...] que o desenvolvimento de competências depende mais de critérios qualitativos delineados pela interação entre aprendizado cognitivo $e$ emocional, os estágios de carreira $e$ as diferentes formas de aprendizado ocupacionais. (CARDOSO, 2009, p. 152)

Isso porque as dimensões ambiente e contexto (espaço onde acontece a interação) e tempo (que determina a experiência) são fundamentais no desenvolvimento dos gestores.

Como contribuição do estudo para os profissionais das áreas de educação e de desenvolvimento gerencial, sugere-se um debate acerca de alternativas para suprir carências no campo das competências sociais, esfera não contemplada pela educação formal. Embora, no presente estudo, não tenham sido observadas distinções significativas entre os pesquisados participantes de curso de MBA e os participantes de mestrado acadêmico, fica a sugestão, como agenda de estudos futuros, uma investigação que examine com maior profundidade esse aspecto.

\section{REFERÊNCIAS}

ANTONACOPOULOU, E. The relationship between individual and organizational learning: new evidence from managerial learning practices. Management Learning, London, England, v. 37, n. 4, p. 455-473, 2006.

Making the business school more "critical": reflexive critique based on phronesis as a foundation for impact. British Journal of Management, New Jersey, United States, v. 21, S-6-S25, 2010.

\section{ANTONELLO, C. Alternativas de articulação entre} programas de formação gerencial e as práticas de trabalho: uma contribuição no desenvolvimento de competências. 2004. 378f. Tese (Doutorado em Administração) - Programa de Pós-Graduação em Administração, Escola de Administração, Universidade Federal do Rio Grande do Sul, Porto Alegre, 2004. Aprendizagem na ação revisitada e sua noção com a noção de competência. In: INTERNATIONAL MEETING OF THE IBEROAMERICAN ACADEMY OF MANAGEMENT, 4, 2005, Lisboa. Anais... Lisboa: Iberoamerican Academy of Management, 2005.

ARTHUR, M.; DeFILLIPPI, R.; JONES, C. Project-based learning as the interplay of career and company nonfinancial capital. Management Learning, v. 32, n. 1, p. 99-117, 2001.

AXLEY, S.; MCMAHON, T. Complexity: a frontier for management education. Journal of Management

Education, Newbury Park, United States, v. 30, n. 2, p. 295-315, April 2006.

CLARK, M.; CAFFARELLA, R. Theorizing adult development. New Directions for Adult and Continuing Education, San Francisco, United States, n. 84, 1999.

CARDOSO, A. L. J. Percepções de gestores sobre competências gerenciais em diferentes contextos REBRAE. Revista Brasileira de Estratégia, Curitiba, v. 2, n. 2, p. 147-169, maio-ago. 2009 
CLOSS, L.; ANTONELLO, C. O uso da história de vida para compreender processos de aprendizagem gerenciais.

Revista de Administração Mackenzie, São Paulo, v. 12, n. 4, p.44-74, 2011.

\section{CRANTON, P. Understanding and promoting} transformative learning: a guide for educators of adults. San Francisco: Jossey-Bass, 2006.

CUNLIFFE, A. On becoming a critically reflexive practicioner. Journal of Management Education, Newbury Park, United States, v. 28, n. 4, Aug. 2004.

The philosopher leader: on relationalism, ethics, and reflexivity - a critical perspective to teaching leadership. Management Learning, v. 40, n. 1, p. 87 102, 2009.

DANIS, C. Processos de aprendizagem dos adultos numa perspectiva de desenvolvimento. In: DANIS, C.; SOLAR, C. (Coord.). Aprendizagem e desenvolvimento dos adultos. Lisboa: Instituto Piaget, 2001. p. 21-93.

DANIS, C.; SOLAR, C. Aprendizagem e desenvolvimento dos adultos: uma perspectiva. In: (Coord.).

Aprendizagem e desenvolvimento dos adultos. Lisboa: Instituto Piaget, 2001. p. 11-20.

DEMARTINI, Z. B. F. Histórias de vida na abordagem de problemas educacionais. In: SIMSON, O.M. V. (Org.).

Experimentos com histórias de vida: Itália-Brasil. São Paulo: Vértice, 1988.

DENZIN, N. K. Interpretive biography. Newbury Park: Sage Publications, Inc., 1989.

D'AMICO, S. M.; MONTEIRO J. K. Características de Personalidade e Qualidade de Vida. Revista de

Administração Contemporânea, Rio de Janeiro, v. 16, n. 3, p. 381-396, maio-jun. 2012.

ELKJAER, B. Pragmatism: a lived and living philosophy. What can it offer to contemporary organization theory? Research in the Sociology of Organizations, Bingley, United, v. 32, p. 55-84, 2011.

GHERARDI, S.; NICOLINI, D. The sociological foundations of organizational learning. In: DIERKES, M.; NONAKA, I.; CHILD, J.; ANTAL, A. Handbook of organizational learning and knowledge. Oxford: Oxford University Press, 2001.
GHERARDI, S.; NICOLINI, D.; ODELLA, F. Toward a social understanding of how people learn in organizations: the notion of situated curriculum. Management Learning, v. 29, n. 3, p. 273-297, 1998.

HRIMECH, M. O desenvolvimento da especialização no adulto. In: DANIS, C.; SOLAR, C. (Coord.).

Aprendizagem e desenvolvimento dos adultos. Lisboa: Instituto Piaget, p. 217-253, 2001.

HUBERMAN, M. O ciclo de vida profissional dos professores. In: NÓVOA, A. Vidas de professores. 2. ed. Porto: Porto Editora, p. 31-61, 1992.

KHATRI, N.; NG, H. The role of intuition in strategic decision making. Human Relations, New York, united States v. 53, n.1, p. 57-86, 2000.

KNOWLES, M. Self-direct learning: a guide for learners and teachers. Chicago: Follet Publishing Company, 1975.

MACLEAN, M.; HARVEY, C.; CHIA, R. Sensemaking, storytelling and the legitimization of elite business careers. Human Relations, New York, united States, v. 65, n.1, p. 17-40, 2012a.

Reflexive practice and the making of elite business careers. Management Learning, v. 43, n. 4, p. 385-404, $2012 b$.

MARSICK, V.; WATKINS, K. Informal and incidental learning. New Directions for Adult and Continuing Education, San Francisco, United States, n. 89, p. 25-34, 2001.

MARSICK, V. Informal strategic learning in the workplace. In: STREUMER, J. (Ed.). Work-related learning, Netherlands: Springer, p. 51-69, 2006.

MERRIAM, S.; CAFFARELLA, R. Learning in adulthood: a comprehensive guide. 2. ed. San Francisco: Jossey-Bass, 1999.

MERRIAM, S.; CLARK, M. Lifelines: Patterns of work, love and learning in adulthood. San Francisco: JosseyBass Publishers, 1991.

MEZIROW, J. Understanding transformation theory. Adult Education Quarterly, Manhattan, United States, v. 44, n. 4, p. 222-232, 1994. 
MORIN, E. Ciência com consciência. Rio de Janeiro: Bertrand, 2003.

ORVIS, K.; RATWANI, K. Leader self-development: a contemporary context for leader development evaluation. The Leadership Quarterly, Philadelphia, United States, v. 21, n. 4 , p. 657-674, 2010.

QUEIROZ, M. I. P. Relatos orais: do "indizível" ao "dizível". In: SIMSON, O. (Org.). Experimentos com

histórias de vida: Itália-Brasil. São Paulo: Vértice, 1988.

RABIA, S.; CHRISTOPOULOS, T. P. Incompatibilidade entre vida pessoal e vida profissional dosgestores na era do conhecimento. Revista de Gestão USP, São Paulo, v. 15, n 3, p. 37-54, 2008.

REBELO, T. Conditioning factors of an organizational learning culture. Journal of Workplace Learning, Bingley, United Kingdom, v. 23, n. 3, 2011.

SCHÖN, D. Educando o profissional reflexivo: um novo design para o ensino e a aprendizagem. Porto Alegre: Artmed, 2000.

SILVA, A. O contexto social da aprendizagem de gerentes. Revista de Administração Mackenzie, São Paulo, v. 9, n. 6, p. 26-52, 2008.

SILVA, L.; SILVA, A. A reflexão como mediadora da aprendizagem gerencial em organizações não governamentais. Revista de Administração

Mackenzie, São Paulo, v. 12, n. 2, p. 55-89, 2011.

SPINK, M. J.; LIMA, H. Rigor e visibilidade: a explicitação dos passos da interpretação. In: SPINK, M. J. (Org.).

Práticas discursivas e produção de sentidos no cotidiano: aproximações teóricas e metodológicas. São Paulo: Cortez, 2000.

XING, Y.; SIMS, D. Leadership, Daoist Wu Wei and reflexivity. Management Learning, v. 43, n.1, p. 97-112. 2012.

WINTERTON, J.; WINTERTON, R. Developing managerial competence. London: New York: Routledge, 1999.
WOOD JR, T.; PAULA, A.P. O fenômeno dos MPAs brasileiros: hibridismo, diversidade e tensões. Revista de Administração de Empresas, São Paulo, v. 44, n. 1, jan.-mar., 2004. 